\title{
Síntese, caracterização e performance catalítica de nanoferritas mistas submetidas a reação de transesterificação e esterificação via rota metílica e etílica para biodiesel
}

\section{Synthesis, Characterization and Catalytic Performance of Mixed Nanoferrites Submitted to Transesterification and Esterification Reaction Using Methyl and Ethyl Route for Biodiesel Production}

\author{
Joelda Dantas ${ }^{1}$, Elvia Leal ${ }^{1}$, Antônio Benjamim Mapossa ${ }^{1}$, Adriano Sant'Ana Silva ${ }^{1}$, \\ Ana Cristina Figueiredo de Melo Costa ${ }^{1}$
}

\author{
${ }^{1}$ Laboratório de Síntese de Materiais Cerâmicos (LabSMaC) - UAEMa/UFCG. Av. Aprígio Veloso - 882, Bodocongó, \\ 58109-970, Campina Grande - PB, Brasil \\ e-mails: joeldadantas@yahoo.com.br; elvialeal@gmail.com; mapossabenjox@gmail.com; \\ adriano_santana@yahoo.com.br; ana.cristina@pq.cnpq.br
}

\begin{abstract}
RESUMO
As nanoferritas mistas de $\mathrm{Ni}_{0,5} \mathrm{Zn}_{0,5} \mathrm{Fe}_{2} \mathrm{O}_{4} \mathrm{e} \mathrm{Ni}_{0,2} \mathrm{Cu}_{0,3} \mathrm{Zn}_{0,5} \mathrm{Fe}_{2} \mathrm{O}_{4}$ foram sintetizadas por reação de combustão usando ureia como combustível e um reator cônico como fonte de aquecimento para produção em bateladas de $10 \mathrm{~g}$, e então, testadas como nanocatalisadores heterogêneos nas reações de transesterificação e esterificação metílica e etílica do óleo de soja para produção de biodiesel. Durante as sínteses foram registrados o tempo e a temperatura das reações, bem como observadas a liberação de gases e a cor das chamas emitidas. As amostras foram caracterizadas por DRX, EDX, FTIR, MEV/EDS, BET e cromatografia gasosa. Os testes reacionais foram executados para $10 \mathrm{~g}$ do óleo em duração de $1 \mathrm{~h}$, razão molar 1:12 óleo:álcool, $2 \%$ (m/m) de catalisador e conduzidas a $180^{\circ} \mathrm{C}$. Os difratogramas de DRX e os espectros de FTIR revelaram presença da fase espinélio inverso tipo $\mathrm{B}(\mathrm{AB})_{2} \mathrm{O}_{4}$. A morfologia apresentou a formação de aglomerados de aspecto frágil e elevada área de superfície. As análises cromatográficas produziram excelentes resultados nas reações de esterificação para ambas amostras nas condições testadas, com destaque especial para $\mathrm{Ni}_{0,5} \mathrm{Zn}_{0,5} \mathrm{Fe}_{2} \mathrm{O}_{4}$, cujas conversões foram de 91,4\% em ésteres metílicos e de 77,8 \% em ésteres etílicos, enquanto que a amostra $\mathrm{Ni}_{0,2} \mathrm{Cu}_{0,3} \mathrm{Zn}_{0,5} \mathrm{Fe}_{2} \mathrm{O}_{4}$ apresentou conversões de 75,1 e 65,1\%, respectivamente. As conversões na transesterificação metílica e etílica foram de 14 e $2 \%$ para $\mathrm{Ni}_{0,5} \mathrm{Zn}_{0,5} \mathrm{Fe}_{2} \mathrm{O}_{4}$ e de 11 e $3 \%$ para $\mathrm{Ni}_{0,2} \mathrm{Cu}_{0,3} \mathrm{Zn}_{0,5} \mathrm{Fe}_{2} \mathrm{O}_{4}$.
\end{abstract}

Palavras-Chave: Ferritas mistas, reação de combustão, nanocatalisadores, transesterificação, esterificação, biodiesel.

\section{ABSTRACT}

The mixed nanoferrites of $\mathrm{Ni}_{0.5} \mathrm{Zn}_{0.5} \mathrm{Fe}_{2} \mathrm{O}_{4}$ and $\mathrm{Ni}_{0.2} \mathrm{Cu}_{0.3} \mathrm{Zn}_{0.5} \mathrm{Fe}_{2} \mathrm{O}_{4}$ were synthesized by combustion reaction using urea as fuel and a conical reactor as heating source in batches of $10 \mathrm{~g}$, and then tested as heterogeneous nanocatalysts in the transesterification and esterification reaction of soya bean oil using the methyl and ethyl routes to biodiesel production. During the synthesis the time and temperature of the reactions were measured, and the evolved gases and the color of the emitted flames were observed. The samples were characterized by XRD, EDX, FTIR, SEM/EDS, BET and gas chromatography. The reaction tests were carried out with $10 \mathrm{~g}$ of oil for $1 \mathrm{~h}$, oil:alcohol molar ratio of $1: 12,2 \%(\mathrm{w} / \mathrm{w})$ of catalyst, and conducted at $180{ }^{\circ} \mathrm{C}$. The XRD patterns and the FTIR spectra revealed the presence of the inverse spinel phase type $\mathrm{B}(\mathrm{AB})_{2} \mathrm{O}_{4}$. The morphology showed the formation of agglomerates with fragile morphology and high surface area. The chromatographic analysis produced excellent results in the esterification reactions for both samples in the tested conditions, with special emphasis on $\mathrm{Ni}_{0.5} \mathrm{Zn}_{0.5} \mathrm{Fe}_{2} \mathrm{O}_{4}$, whose conversions were of $91.4 \%$ in methyl esters and of $77.8 \%$ in ethyl esters, while the $\mathrm{Ni}_{0.2} \mathrm{Cu}_{0.3} \mathrm{Zn}_{0.5} \mathrm{Fe}_{2} \mathrm{O}_{4}$ sample showed conversion of 75.1 and $65.1 \%$, respectively. 
The conversions in the methyl and ethyl transesterification were of 14 and $2 \%$ of the $\mathrm{Ni}_{0.5} \mathrm{Zn}_{0.5} \mathrm{Fe}_{2} \mathrm{O}_{4}$ sample, and of 11 and $3 \%$ for the $\mathrm{Ni}_{0.2} \mathrm{Cu}_{0.3} \mathrm{Zn}_{0.5} \mathrm{Fe}_{2} \mathrm{O}_{4}$ sample.

Keywords: Mixed ferrites, combustion reaction, nanocatalysts, transesterification, esterification, biodiesel.

\section{INTRODUÇÃO}

A nível mundial os apelos com relação a preservação do meio ambiente tem ecoado potencialmente, de maneira que o uso da biomassa vem ganhando expressiva relevância devido a possibilidade de ser utilizada na produção de calor, seja para uso térmico industrial, seja para geração de eletricidade e/ou por poder ser transformada em outras formas de energias sólidas (carvão vegetal), líquidas (bioetanol, biodiesel, bio-óleo) e gasosas (biogás). Dentre a geração dos produtos renováveis obtidos da biomassa, a exemplo dos biocombustíveis, o biodiesel vem recebendo especial destaque por apresentar características como baixa toxicidade e baixa emissão de gases poluentes. WELDEMICHAEL e ASSEFA [1] relataram que a utilização de biomassa para produção de energia promove o desenvolvimento sustentável através da economia de energia com base em combustíveis fósseis e reduz os gases de efeito estufa (GEE).

O biodiesel é considerado uma das fontes renováveis em alta expansão para substituição do diesel fóssil no Brasil [2], tendo em vista que no cenário brasileiro, além do benefício ambiental, a produção de biodiesel reduz a necessidade de importação de óleo diesel, favorecendo o resultado de nossa balança comercial.

Concernente à produção de biodiesel, dentre os processos químicos utilizados, os principais são a transesterificação e a esterificação. Na transesterificação, um triacilglicerídeo reage com um álcool na presença de um ácido ou de uma base forte, produzindo uma mistura de ésteres alquílicos dos ácidos graxos e de glicerol. Enquanto, na esterificação, ocorre uma reação entre ácidos carboxílicos e um álcool de cadeia curta, em presença de catalisador ácido, produzindo ésteres com eliminação de água.

Ambas reações de transesterificação e de esterificação são controladas por diversos parâmetros, tais como, temperatura, razão óleo:álcool, tipo e quantidade de catalisador, tempo da reação, qualidade da matéria-prima e também o tipo do álcool utilizado nestas reações influenciam a obtenção do produto final, que é o biodiesel. De sorte que, avaliar como estes parâmetros influenciam as reações, é de suma importância, uma vez que o custo final deste biocombustível é uma das principais preocupações nas biorrefinarias. Conforme KONWAR et al. [3], a composição da matéria-prima influencia a solubilidade entre álcool e óleo.

Além da razão molar óleo:álcool, o tipo de álcool utilizado deve ser levado em consideração nas reações de transesterificação e esterificação. Para a produção de biodiesel podem ser utilizados diferentes alcóois, como o metanol, etanol, propanol, butanol e o álcool amílico. Porém, do ponto de vista comercial, os alcoóis metílicos e etílicos são os mais utilizados. Ademais, o metanol é o álcool mais utilizado na obtenção do biodiesel, em virtude de seu baixo custo e facilidade de obtenção, entretanto, buscar a viabilização do etanol na cadeia produtiva do biodiesel, fundamenta-se no fato do Brasil ser um dos maiores produtores mundiais deste álcool e na baixa toxidade do álcool etílico frente ao metanol.

O metanol é mais frequentemente utilizado também por razões de natureza física e química (cadeia curta e polaridade). Conforme DEMIRBAS [4], quanto maior a cadeia molecular do álcool utilizado nas reações de transesterificação e esterificação, menor conversão em biodiesel. Quando a cadeia molecular aumenta, a quebra da molécula do triacilglicerídeo, em éster e glicerol, é menos eficiente. Na etanólise ocorre a formação de emulsão estável e indesejável durante as reações. Entretanto, na metanólise, as emulsões são facilmente separadas em duas fases, uma inferior, que é o glicerol e outra superior rica em ésteres, enquanto na etanólise elas são mais estáveis e severas dificultando a separação e purificação dos ésteres.

Em ambas reações de transesterificação e esterificação, o uso de catalisadores sólidos tem se tornado cada vez mais promissor diante da possibilidade de recuperação e reuso além destes materiais apresentarem as características físicas e químicas, como sítios ácidos e básicos de Lewis e Brönsted e área superficial favorável para a execução destas reações. Desta maneira, um dos grandes desafios que as empresas de pesquisas industriais têm enfrentado atualmente, tem sido o desenvolvimento de catalisadores para produção de biodiesel, que apresentem juntamente alta atividade e seletividade nas reações de transesterificação e esterificação.

Catalisadores heterogêneos a base de óxidos ternários com características magnéticas, como as ferritas espinélios, tipo $\mathrm{AB}_{2} \mathrm{O}_{4}$, são uma proposta alternativa promissora, pois a separação magnética evita perda do material e aumenta o tempo de reuso [5]. Tanto é assim que vários estudos vêm sendo desenvolvidos com o uso de ferritas como catalisadores para biodiesel [6-11].

As pesquisas pioneiras neste âmbito foram desenvolvidas no laboratório de síntese de materiais cerâmicos (LabSMaC), e como resultados foram relatados desempenhos favoráveis e promissores de nanoferritas obtidas via síntese por reação de combustão, com expressiva aplicação na preparação de biodiesel [11], pois além da fácil separação do meio reacional, as nanoferritas apresentam elevada área de contato, alta estabili- 
dade térmica e boas propriedades químicas, culminando assim numa participação mais efetiva nas reações químicas para produzir biodiesel. Vários autores relatam sobre as excelentes propriedades intrínsecas e extrínsecas das ferritas, e porque devido a isto são possíveis inúmeras aplicações tecnológicas [12-16]. Dentre as ferritas testadas preliminarmente como nanocatalisadores sólidos, estão diferentes composições de ferritas mistas de (Ni-Cu-Zn) $\mathrm{Fe}_{2} \mathrm{O}_{4}$ [17,18]; $(\mathrm{Ni}-\mathrm{Zn}) \mathrm{Fe}_{2} \mathrm{O}_{4}$ [19] e $(\mathrm{Cu}-\mathrm{Zn}) \mathrm{Fe}_{2} \mathrm{O}_{4}$ [20], e as ferritas simples de $\mathrm{MnFe}_{2} \mathrm{O}_{4} ; \mathrm{NiFe}_{2} \mathrm{O}_{4} \mathrm{e} \mathrm{CoFe} \mathrm{O}_{4}$ [21,22]. Avaliando as ferritas testadas entre si, as composições indicadas mais promissoras foram as ferritas mistas $\mathrm{Ni}_{0,5} \mathrm{Zn}_{0,5} \mathrm{Fe}_{2} \mathrm{O}_{4} \mathrm{e} \mathrm{Ni}_{0,2} \mathrm{Cu}_{0,3} \mathrm{Zn}_{0,5} \mathrm{Fe}_{2} \mathrm{O}_{4}$.

Dentro desta abordagem, este trabalho propõe realizar um estudo sistemático e comparativo do desempenho catalítico das ferritas mistas $\mathrm{Ni}_{0,5} \mathrm{Zn}_{0,5} \mathrm{Fe}_{2} \mathrm{O}_{4}$ e $\mathrm{Ni}_{0,2} \mathrm{Cu}_{0,3} \mathrm{Zn}_{0,5} \mathrm{Fe}_{2} \mathrm{O}_{4}$ como nanocatalisadores nas reações químicas de transesterificação e esterificação metílica e etílica do óleo de soja para produção de biodiesel.

\section{MATERIAIS E MÉTODOS}

A síntese das nanoferritas por reação de combustão envolveu a mistura de sais de íons metálicos como reagentes oxidantes (nitratos de níquel - $\mathrm{Ni}\left(\mathrm{NO}_{3}\right)_{2} \cdot 6 \mathrm{H}_{2} \mathrm{O}$ e zinco hexahidratado $-\mathrm{Zn}\left(\mathrm{NO}_{3}\right)_{2} \cdot 6 \mathrm{H}_{2} \mathrm{O}$, nitrato de ferro nonohidratado - $\mathrm{Fe}\left(\mathrm{NO}_{3}\right)_{3} \cdot 9 \mathrm{H}_{2} \mathrm{O}$ e nitrato de cobre II - $\left.\mathrm{Cu}\left(\mathrm{NO}_{3}\right)_{2} \cdot 3 \mathrm{H}_{2} \mathrm{O}\right)$ e ureia - $\left(\mathrm{NH}_{2}\right)_{2} \mathrm{CO}$ como agente redutor, de modo a formar uma solução redox. Todos os reagentes com grau de pureza entre 98 e $99 \%$ e em quantidades de 14,54; 14,87; 80,80 e 6,06 g/mol, respectivamente. A composição inicial da solução foi calculada baseada na valência total dos reagentes oxidantes e redutores, utilizando conceitos da química dos propelentes e explosivos [23].

As reações foram realizadas em um recipiente com capacidade volumétrica de 2 litros e capacidade de produção em bateladas de $10 \mathrm{~g}$ do produto final, e submetidas ao aquecimento direto em reator cônico [24], até a ocorrência da autoignição (combustão). Durante a síntese foram feitas aferições da temperatura e do tempo de chama da combustão. As temperaturas das reações de combustão foram medidas em um intervalo de tempo de 5 em 5 segundos entre cada medição, de forma on-line, de acordo com a calibração do aparelho e seu software de registro. Para tal procedimento fez-se uso de um pirômetro de infravermelho (Raytek, modelo RAYR3I $\pm 2{ }^{\circ} \mathrm{C}$ ). $\mathrm{O}$ tempo de chama da combustão foi medido com um cronômetro digital (marca Technos). Após as sínteses, os produtos obtidos (nanoferritas mistas $\mathrm{Ni}_{0,5} \mathrm{Zn}_{0,5} \mathrm{Fe}_{2} \mathrm{O}_{4}$ e $\mathrm{Ni}_{0,2} \mathrm{Cu}_{0,3} \mathrm{Zn}_{0,5} \mathrm{Fe}_{2} \mathrm{O}_{4}$ ) foram desaglomerados em almofariz e passados em peneira com malha \#325 ABNT (abertura de $45 \mu \mathrm{m}$ ). As etapas da síntese, do início até a obtenção do produto final (pó), estão ilustradas de forma básica na Figura 1.

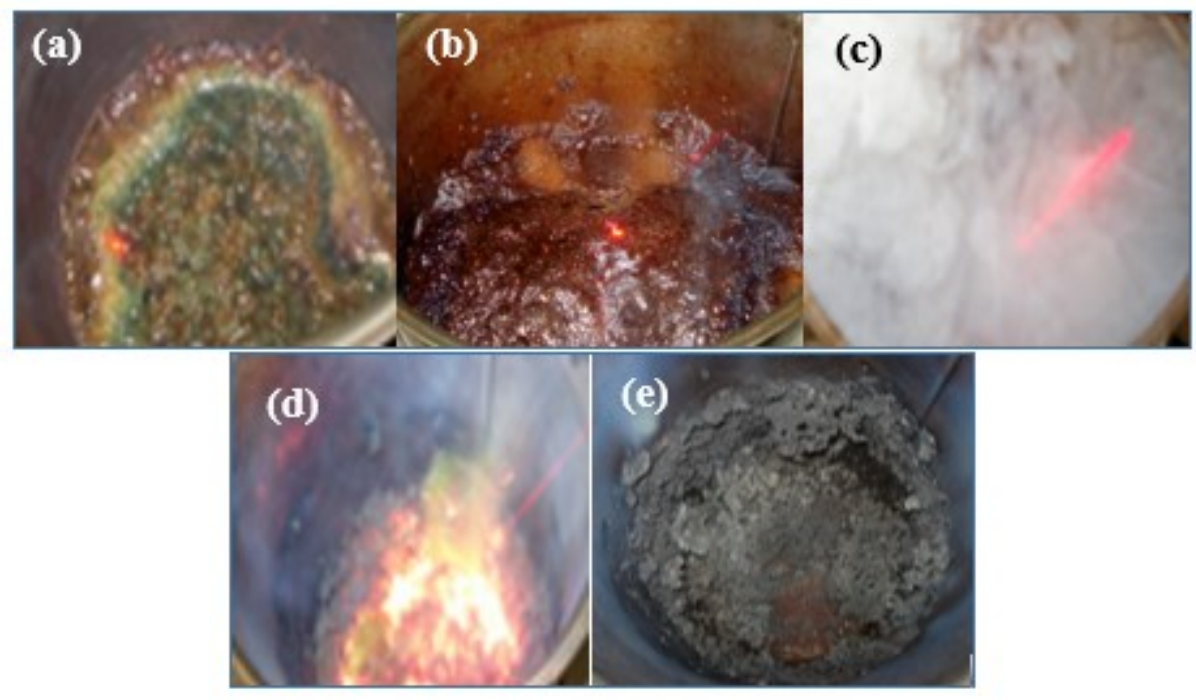

Figura 1: Imagens do produto obtido via síntese por reação de combustão.

As amostras foram caracterizadas por difração de raios X (DRX), usando um difratômetro de raios X, da marca Shimadzu e modelo XRD 6000, com fonte de radiação $\mathrm{CuK \alpha} \alpha, \lambda=1,542 \AA$, tensão de $40 \mathrm{kV}$, corrente de $30 \mathrm{~mA}$ e varredura de 15 a $85^{\circ} \mathrm{C}$, para determinação das fases formadas e tamanho de cristalito. $\mathrm{O}$ tamanho de cristalito foi calculado a partir do alargamento de raios-X $\left(\mathrm{d}_{311}\right)$, mediante a deconvolução da linha de difração secundária do cério policristalino (utilizado como padrão) utilizando-se a equação de SCHERRER [25]. A Espectroscopia na região do infravermelho com transformada de Fourier (FTIR) foi 
realizada em pastilhas de $\mathrm{KBr}$ a $1 \%$ (em massa), usando um espectrômetro Shimadzu Spectrum BX - Perkin Elmer, com comprimento de onda entre $4000 \mathrm{e} 400 \mathrm{~cm}^{-1}$, com resolução de $4 \mathrm{~cm}^{-1}$ e 20 varreduras. Esta técnica foi utilizada para observar as bandas características da fase espinélio em estudo. Os aspectos morfológicos das amostras foram analisados por meio de Microscopia Eletrônica de Varredura (MEV), em um microscópio modelo SSX 550 Superscan-Shimadzu, operando em 15kV.

As reações de transesterificação e esterificação foram conduzidas em um reator de aço inox, o qual encamisa um copo de borosilicato de volume útil de $80 \mathrm{~mL}$, pressurizado, composto de um duto para entrada de termopar e acoplado a um manômetro. A agitação e o aquecimento do sistema foram promovidos por uma placa com aquecimento e agitação magnética. A reação de transesterificação foi realizada utilizando como matéria prima óleo de soja refinado (neutro). Na reação de esterificação foi utilizada uma mistura modelo consistindo de óleo de soja refinado, acidificado artificialmente com $15 \%$ em peso de ácido oleico, intencionando simular uma matéria prima com alto índice de acidez. Este valor foi adotado como referência, devido a certas gorduras regionais (óleo de mamona, sebos de matadouro e óleo de fritura) apresentarem teores entre 10-20\% de ácidos graxos livres. As razões molares de álcool metílico e etílico mais o ácido graxo foram de 12:1, foi utilizado $2 \%$ em massa de catalisador em relação ao ácido graxo. Os testes reacionais foram efetuados a $180^{\circ} \mathrm{C}$ com tempo reacional de 1 hora. O produto obtido em ambas reações (Figura 2) foi analisado em cromatógrafo a gás Varian 450c, com detector de ionização de chamas (FID), coluna capilar de fase estacionária Varian Select Biodiesel Glycerides $+R G$ (Ultimetal) $(15 \mathrm{~m} \times 0,32 \mathrm{~mm} \times 0,45 \mu \mathrm{m})$. A temperatura inicial para a injeção foi de $100{ }^{\circ} \mathrm{C}$ e a do forno foi de $180^{\circ} \mathrm{C}$. O detector operou em temperatura de $380{ }^{\circ} \mathrm{C}$.

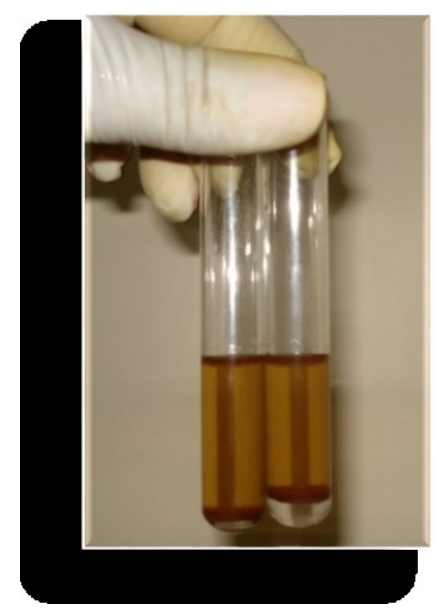

Figura 2: Imagem dos produtos reacionais (biodiesel).

\section{RESULTADOS E DISCUSSÕES}

No decorrer das sínteses por reação de combustão, o tempo de chama, o tempo de reação e a temperatura de chama da combustão foram aferidos e se encontram descritos na Tabela 1. Observa-se de forma geral que a temperatura máxima alcançada durante as sínteses foi inferior a $1000{ }^{\circ} \mathrm{C}$ e que as reações ocorreram num tempo curto de $210 \mathrm{~s}$, logo, o processo empregado para síntese das nanoferritas $\mathrm{Ni}_{0,5} \mathrm{Zn}_{0,5} \mathrm{Fe}_{2} \mathrm{O}_{4} \mathrm{e}$ $\mathrm{Ni}_{0,2} \mathrm{Cu}_{0,3} \mathrm{Zn}_{0,5} \mathrm{Fe}_{2} \mathrm{O}_{4}$ foi eficaz para formação do produto final de forma rápida e simples. Observa-se também um aumento na temperatura de aproximadamente $34 \%$ acompanhada de uma redução de quase $50 \%$ no tempo de chama de combustão, quando comparada a composição da nanoferrita com 0,3 mol de $\mathrm{Cu}^{2+}$ e a nanoferrita sem $\mathrm{Cu}^{2+}$. O tempo total reacional foi o mesmo para ambas amostras estudadas.

Tabela 1: Parâmetros obtidos durante as sínteses por reação de combustão das amostras.

\begin{tabular}{ccc}
\hline \hline NANOFERRITAS & $\mathbf{N i}_{0,5} \mathbf{Z n}_{0,5} \mathrm{Fe}_{2} \mathbf{O}_{\mathbf{4}}$ & $\mathbf{N i}_{0,2} \mathbf{C u}_{0,3} \mathbf{Z n}_{0,5} \mathbf{F e}_{2} \mathbf{O}_{4}$ \\
\hline \hline Cor da chama & Amarela & Verde \\
Tempo de chama (s) & 123 & 61 \\
Temperatura de chama máx. $\left({ }^{\circ} \mathrm{C}\right)$ & 646 & 975 \\
Tempo total de reação (s) & 210 & 210 \\
\hline \hline
\end{tabular}

$\mathrm{O}$ valor de $646{ }^{\circ} \mathrm{C}$ da temperatura de chama de combustão para a amostra sem cobre $\left(\mathrm{Ni}_{0,5} \mathrm{Zn}_{0,5} \mathrm{Fe}_{2} \mathrm{O}_{4}\right)$, foi inferior ao valor reportado por COSTA [26], que foi de $703{ }^{\circ} \mathrm{C}$, quando estudou a obtenção deste mesmo 
sistema por reação de combustão usando como recipiente um cadinho de sílica vítrea e fonte de aquecimento uma placa cerâmica com aquecimento. Então, isto mostra que a utilização do recipiente com capacidade de produção de $10 \mathrm{~g}$ por bateladas acoplado ao reator cônico favoreceu a obtenção de valores mais baixos de temperatura de combustão e com uma maior quantidade de produto final. Possivelmente, esta diferença pode ser atribuída ao tipo de material do recipiente utilizado que foi o aço inoxidável, o qual transporta o calor da fonte externa de aquecimento (reator cônico) com maior rapidez e também a maior quantidade de reagentes utilizados na síntese, o que acelera a cinética reacional e assim contribuem para maior liberação de gás de combustão, tendendo a gerar menores temperaturas de combustão.

Agora, concernente ao parâmetro cor de chama, foi possível verificar durante o desenvolvimento experimental das reações de combustão, uma mudança na coloração da chama, de amarela para esverdeada com a dopagem de 0,3 mol de cobre. A Figura 3 ilustra a sequência das sínteses, bem como a coloração da chama de combustão para as amostras. Observa-se que o $\mathrm{Cu}^{2+}$ ao ser incrementado no sistema da ferrita pura em substituição ao $\mathrm{Ni}^{2+}$, tornou a chama verde.

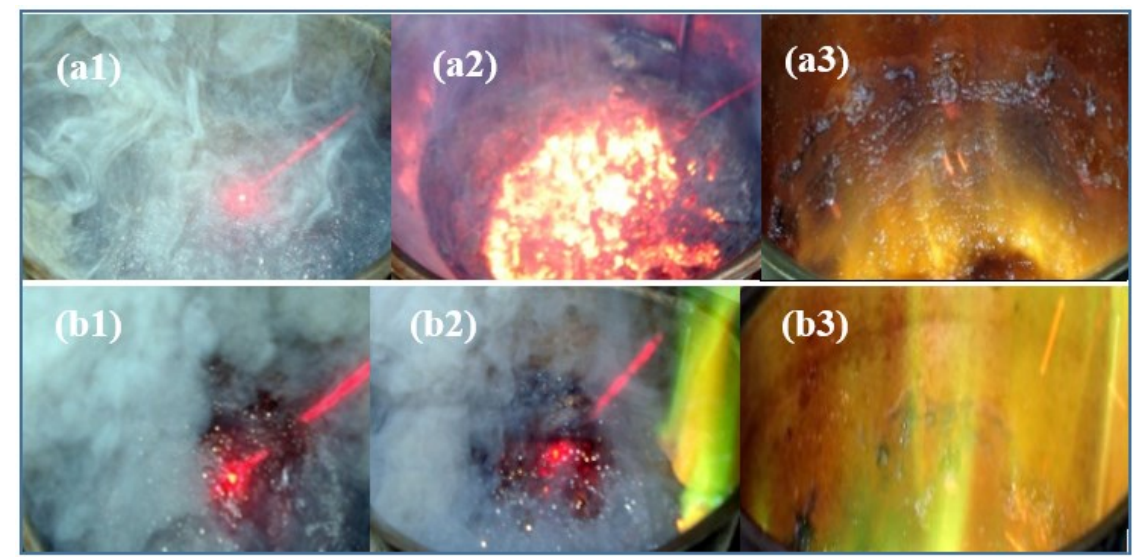

Figura 3: Imagens das reações de combustão, para: (a) $\mathrm{Ni}_{0,5} \mathrm{Zn}_{0,5} \mathrm{Fe}_{2} \mathrm{O}_{4}-$ chama amarela e (b) $\mathrm{Ni}_{0,2} \mathrm{Cu}_{0,3} \mathrm{Zn}_{0,5} \mathrm{Fe}_{2} \mathrm{O}_{4}-$ chama esverdeada.

A Figura 4 ilustra os difratogramas de raios $X$ das nanoferritas $\mathrm{Ni}_{0,5} \mathrm{Zn}_{0,5} \mathrm{Fe}_{2} \mathrm{O}_{4}$ e $\mathrm{Ni}_{0,2} \mathrm{Cu}_{0,3} \mathrm{Zn}_{0,5} \mathrm{Fe}_{2} \mathrm{O}_{4}$. Em ambas, observou-se apenas a presença dos picos principais característicos da estrutura do espinélio inverso, evidenciada pelo aparecimento do pico principal $2 \theta=35,5^{\circ}$, conforme ficha cristalográfica JCPDF 52 0278. Também, se verifica picos com alta intensidade e elevada largura basal para todas as reflexões, revelando a cristalinidade das amostras e suas características nanoestruturais.

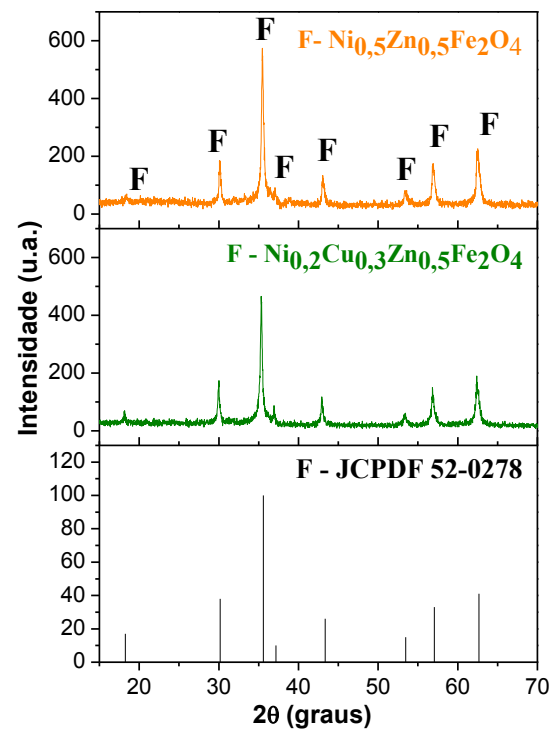

Figura 4: Padrões de DRX referente às amostras: (a) $\mathrm{Ni}_{0,5} \mathrm{Zn}_{0,5} \mathrm{Fe}_{2} \mathrm{O}_{4} \mathrm{e}$ (b) $\mathrm{Ni}_{0,2} \mathrm{Cu}_{0,3} \mathrm{Zn}_{0,5} \mathrm{Fe}_{2} \mathrm{O}_{4}$. 
A cristalinidade e o tamanho de cristalito calculado a partir dos dados de DRX foram de 74 e $70 \%$ e 26 e $34 \mathrm{~nm}$, respectivamente, comprovando assim a eficiência do processo de reação de combustão para obtenção das nanoferritas $\mathrm{Ni}_{0,5} \mathrm{Zn}_{0,5} \mathrm{Fe}_{2} \mathrm{O}_{4}$ e $\mathrm{Ni}_{0,2} \mathrm{Cu}_{0,3} \mathrm{Zn}_{0,5} \mathrm{Fe}_{2} \mathrm{O}_{4}$. Estes resultados corroboram com o trabalho reportado por BATOO e ANSARI [27], quando estudaram nanopartículas de ferrita de composição básica $\mathrm{Ni}_{0.7-\mathrm{x}} \mathrm{Cu}_{0.3} \mathrm{Zn}_{\mathrm{x}} \mathrm{Fe}_{2} \mathrm{O}_{4}$, sintetizadas pelo método da auto-combustão, e obtiveram fase única e com tamanho de cristalito de $28-32 \mathrm{~nm}$.

Quanto ao aumento de aproximadamente $24 \%$ observado no tamanho de cristalito obtido neste trabalho, que cresceu de 26 para $34 \mathrm{~nm}$, pode ser justificado visto a amostra com presença do $\mathrm{Cu}^{2+}$ $\left(\mathrm{Ni}_{0,2} \mathrm{Cu}_{0,3} \mathrm{Zn}_{0,5} \mathrm{Fe}_{2} \mathrm{O}_{4}\right)$ ter alcançado uma maior temperatura de chama de combustão durante a síntese, em detrimento da amostra sem $\mathrm{Cu}^{2+}\left(\mathrm{Ni}_{0,5} \mathrm{Zn}_{0,5} \mathrm{Fe}_{2} \mathrm{O}_{4}\right)$. Essa justificativa é assegurada pelo fato de que quanto maior for à temperatura fornecida ao sistema, maior tendência ao crescimento das partículas e mais forte será à força de ligação, o que leva a formação de agregados e/ou formação de aglomerados densos (sem porosidade interpartícula), como também o incremento de dopantes gera formação de defeitos na rede, o que pode influenciar no tamanho do cristalito.

Característica semelhante foi reportada por GHASEMI et al. [28], quando sintetizaram via micela reversa a mesma ferrita $\mathrm{Ni}$-Zn dopada com cobre. Observaram que com o aumento no teor de cobre, o tamanho das partículas aumentou consideravelmente, de 3-7 nm para dopagem de cobre de $\mathrm{x}=0,0$ e de 30-40 nm para dopagem de cobre de $\mathrm{x}=0,5 \mathrm{~mol}$. Os autores justificaram o aumento em função da adição do dopante.

Na Tabela 2 encontram-se apresentados os resultados da análise semi-quantitativa das nanoferritas $\mathrm{Ni}_{0,5} \mathrm{Zn}_{0,5} \mathrm{Fe}_{2} \mathrm{O}_{4}$ e $\mathrm{Ni}_{0,2} \mathrm{Cu}_{0,3} \mathrm{Zn}_{0,5} \mathrm{Fe}_{2} \mathrm{O}_{4}$. De forma geral, verifica-se que embora seja uma técnica semiquantitativa, a análise destes resultados revelou que as quantidades de cada óxido determinadas experimentalmente apresentam-se próximos aos valores teóricos. As variações observadas podem ser atribuídas as impurezas presentes nos reagentes relatadas pelo fabricante.

Tabela 2: Composição teórica e experimental para as amostras em estudo.

\begin{tabular}{ccccc}
\hline \hline \multirow{2}{*}{ óxIDOS } & \multicolumn{2}{c}{$\mathbf{N i}_{0,5} \mathbf{Z n}_{0,5} \mathbf{F e}_{2} \mathbf{O}_{4}$} & \multicolumn{2}{c}{$\mathbf{N i}_{0,2} \mathbf{C u}_{0,3} \mathbf{Z} \mathbf{n}_{0,5} \mathbf{F e}_{2} \mathbf{O}_{4}$} \\
\cline { 2 - 5 } & $\mathbf{T}(\%)$ & $\mathbf{E}(\%)$ & $\mathbf{T}(\%)$ & $\mathbf{E}(\%)$ \\
\hline \hline $\mathrm{NiO}$ & 15,7 & 16,2 & 6,2 & 6,2 \\
$\mathrm{ZnO}$ & 17,1 & 15,4 & 17,0 & 14,7 \\
$\mathrm{CuO}$ & - & - & 9,9 & 8,4 \\
$\mathrm{Fe}_{2} \mathrm{O}_{3}$ & 67,2 & 68,4 & 66,8 & 70,7 \\
\hline \hline
\end{tabular}

Onde: $\mathrm{T}$ - Valor teórico; E - Valor experimental.

Entretanto, numa análise mais detalhada destes resultados, verifica-se que o teor do óxido de zinco foi o que sofreu uma redução mais expressiva dentre os demais óxidos envolvidos. Verifica-se que o teor do $\mathrm{ZnO}$ tende a reduzir com a substituição parcial do íon cobre $\left(\mathrm{Cu}^{2+}\right)$ pelo íon níquel $\left(\mathrm{Ni}^{2+}\right)$. Tal constatação está relacionada diretamente com a temperatura máxima de combustão, de forma que pode-se atribuir este evento a possível volatilização do $\mathrm{Zn}$ em altas temperaturas, uma vez que o zinco apresenta baixo ponto de fusão $\left(419^{\circ} \mathrm{C}\right)$, então as temperaturas de combustão mais elevadas obtidas nesse trabalho, de 646 e $975^{\circ} \mathrm{C}$, podem facilmente induzir a sua volatilização parcial. Com relação ao teor do $\mathrm{CuO}$, verifica-se uma redução menor em detrimento a que ocorreu para o $\mathrm{ZnO}$, isto possivelmente pode ser atribuído também ao ponto de fusão do $\mathrm{Cu}$ que é de $1085^{\circ} \mathrm{C}$, valor maior que a máxima temperatura da síntese $\left(975^{\circ} \mathrm{C}\right)$, incorrendo numa menor volatização deste elemento.

Na Figura 5 encontram-se ilustrados os espectros vibracionais na região do infravermelho das ferritas mistas $\mathrm{Ni}_{0,5} \mathrm{Zn}_{0,5} \mathrm{Fe}_{2} \mathrm{O}_{4}$ e $\mathrm{Ni}_{0,2} \mathrm{Cu}_{0,3} \mathrm{Zn}_{0,5} \mathrm{Fe}_{2} \mathrm{O}_{4}$. Com base nestes resultados verificou-se a presença das bandas vibracionais $569,1381,1628,2352,2922,3147$ e $3457 \mathrm{~cm}^{-1}$ para ambas amostras estudadas. 
DANTAS, J.; LEAL, E.; MAPOSSA, A.B.; SILVA, A.S.; COSTA, A.C.F.M. revista Matéria, v. 21, n.4, pp. 1080 - 1093, 2016.

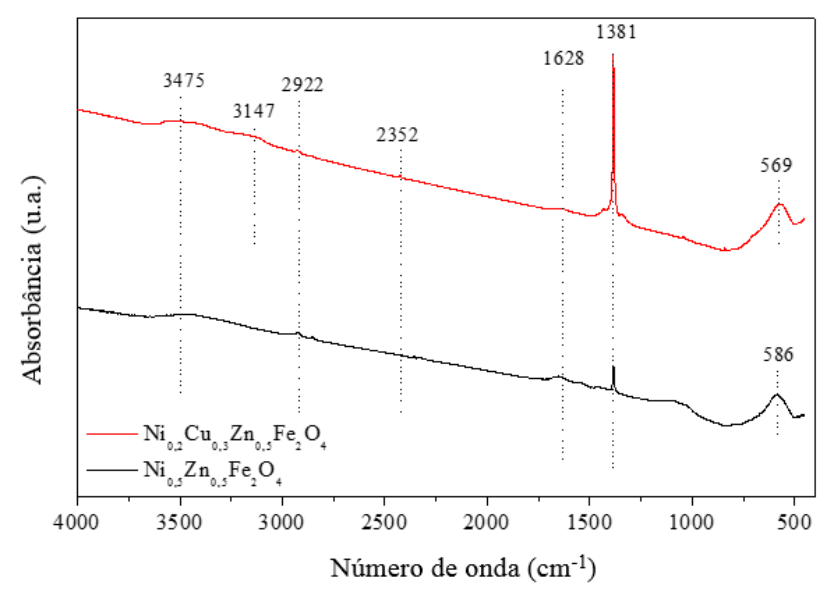

Figura 5: Espectro de FTIR para $\mathrm{Ni}_{0,5} \mathrm{Zn}_{0,5} \mathrm{Fe}_{2} \mathrm{O}_{4}$ e $\mathrm{Ni}_{0,2} \mathrm{Cu}_{0,3} \mathrm{Zn}_{0,5} \mathrm{Fe}_{2} \mathrm{O}_{4}$.

É conhecido que bandas de absorção abaixo de $1000 \mathrm{~cm}^{-1}$ são características do espinélio $\mathrm{AB}_{2} \mathrm{O}_{4}$. Estas bandas são caracterizadas por vibrações de íons na rede do cristal, ou seja, vibrações dos sítios tetraédricos e vibrações dos sítios octaédricos. VELMURUGAN et al. [29], estudando ferritas de Ni-Zn obtidas pelo método de coprecipitação e utilizando espectros de FTIR nas amostras, observaram a presença de bandas características da ferrita do espinélio inverso abaixo de $1000 \mathrm{~cm}^{-1}$. Então, estas bandas de baixa energia (em torno de $400 \mathrm{a} 1000 \mathrm{~cm}^{-1}$ ), conforme a literatura [30] está relacionada às vibrações de estiramento e às vibrações de flexão de coordenação tetraédrica e octaédrica.

Assim, a banda vibracional a $569 \mathrm{~cm}^{-1}$ observada neste trabalho, é atribuída ao estiramento intrínseco de Fe-O no sítio tetraédrico. As demais bandas vibracionais são atribuídas a presença do íon $\mathrm{NO}^{3-}\left(1381 \mathrm{~cm}^{-}\right.$ ${ }^{1}$ ), a água adsorvida (1628 e $3475 \mathrm{~cm}^{-1}$ ) e resíduo de carbono proveniente do agente complexante (ureia).

Além do mais, no tocante as bandas vibracionais referentes ao estiramento intrínseco de $\mathrm{Fe}-\mathrm{O}-$-, observados nos espectros, que para a amostra $\mathrm{Ni}_{0,5} \mathrm{Zn}_{0,5} \mathrm{Fe}_{2} \mathrm{O}_{4}$ ocorreu em $586 \mathrm{~cm}^{-1}$ e para a amostra $\mathrm{Ni}_{0,2} \mathrm{Cu}_{0,3} \mathrm{Zn}_{0,5} \mathrm{Fe}_{2} \mathrm{O}_{4}$ em $569 \mathrm{~cm}^{-1}$, foi observado uma variação nestes valores. Estes desvios se devem, conforme descrito por SHIRSATH et al. [31], às diferentes distâncias da ligação Fe-O- nos sítios tetraédricos e octaédricos para cada amostra. Os autores ainda relatam que esta variação, pode estar relacionada às condições da reação, tamanho do grão, a densidade do material e a presença de agente dopante, como é o caso da amostra $\mathrm{Ni}_{0,2} \mathrm{Cu}_{0,3} \mathrm{Zn}_{0,5} \mathrm{Fe}_{2} \mathrm{O}_{4}$, dopada com cobre $\left(\mathrm{Cu}^{2+}\right)$.

A Figura 6 ilustra os aspectos morfológicos das ferritas mistas $\mathrm{Ni}_{0,5} \mathrm{Zn}_{0,5} \mathrm{Fe}_{2} \mathrm{O}_{4}$ e $\mathrm{Ni}_{0,2} \mathrm{Cu}_{0,3} \mathrm{Zn}_{0,5} \mathrm{Fe}_{2} \mathrm{O}_{4}$, respectivamente. No tocante a morfologia dos materiais o processo de aglomeração das partículas, refere-se à adesão destas entre si por forças de atração fracas como as de Van der Waals, as quais são significativamente maiores em nanopartículas. Conforme REED, [32], materiais aglomerados desta forma, são facilmente desaglomerados em meio líquido ou fisicamente. Por outro lado, a agregação refere-se a partículas que sinterizam incipientemente, tornado difícil a quebra do aglomerado de partículas.

Com base nisto, foi constatado pela morfologia da amostra $\mathrm{Ni}_{0,5} \mathrm{Zn}_{0,5} \mathrm{Fe}_{2} \mathrm{O}_{4}$ (Figura 6a e 6b), a presença de aglomerados na forma de blocos irregulares de aspecto frágil, ou seja, constituída por partículas finas ligadas fracamente (as partículas estão apenas em contato umas com as outras, sem observar présinterização), sendo, portanto, facilmente desaglomeradas e com pouca porosidade proveniente dos gases de combustão.

A baixa porosidade está relacionada a temperatura máxima atingida durante a síntese da ferrita, que chegou apenas a $646^{\circ} \mathrm{C}$, o que respalda a pouca liberação de gases observada experimentalmente. Em temperaturas mais elevadas, há uma maior liberação de gases durante a reação de combustão, de forma a favorecer uma morfologia mais porosa ao material sintetizado. Verificou-se também (por intermédio de medições), aglomerados com tamanho variando entre 8 e $46 \mu \mathrm{m}$, com tamanho médio de $23 \mu \mathrm{m}$ e com uma estreita distribuição de tamanho. 


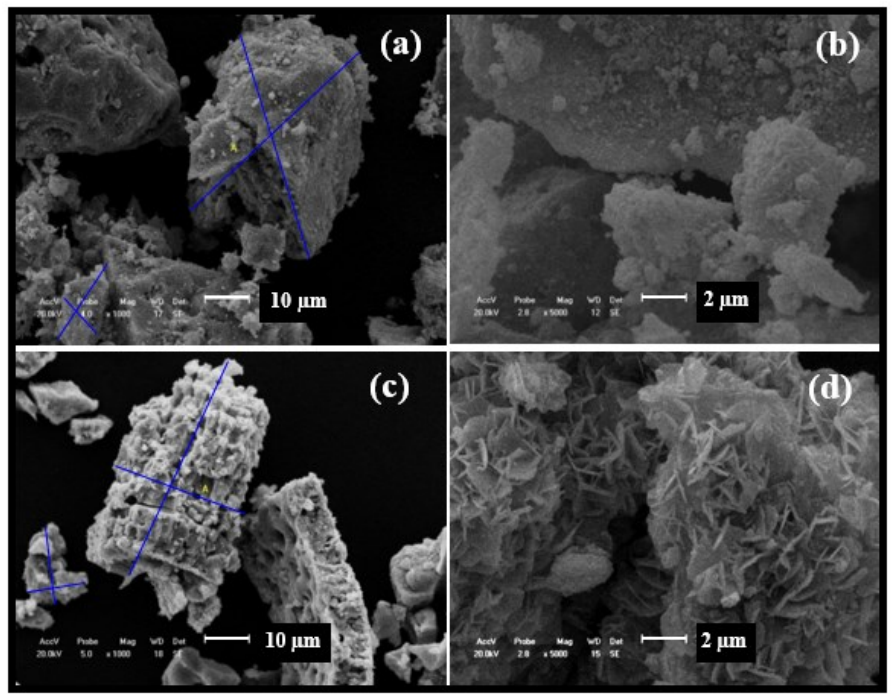

Figura 6: Imagens de MEV das amostras: $\mathrm{Ni}_{0,5} \mathrm{Zn}_{0,5} \mathrm{Fe}_{2} \mathrm{O}_{4}-$ (a) $10 \mu \mathrm{m}$ e (b) $2 \mu \mathrm{m} \mathrm{e} \mathrm{Ni}_{0,2} \mathrm{Cu}_{0,3} \mathrm{Zn}_{0,5} \mathrm{Fe}_{2} \mathrm{O}_{4}-$ (c) $10 \mu \mathrm{m}$ e (d) $2 \mu \mathrm{m}$.

Com relação a amostra $\mathrm{Ni}_{0,2} \mathrm{Cu}_{0,3} \mathrm{Zn}_{0,5} \mathrm{Fe}_{2} \mathrm{O}_{4}\left(\right.$ com $\left.\mathrm{Cu}^{2+}\right)$, por intermédio da Figura $6 \mathrm{c}$ e $6 \mathrm{~d}$, verificou-se uma morfologia constituída pela formação de aglomerados irregulares, com presença de porosidade, o que possivelmente foi ocasionado pela maior evaporação dos gases durante a combustão. Além disso, a formação de cavidades entre os aglomerados e constatação de superfície porosa indica que durante a reação uma grande quantidade de gases foi liberada.

Entretanto, estes aglomerados são também formados por partículas finas ligadas por forças fracas e com baixa porosidade interpartícula. Também se observou aglomerados de partículas no formato de placas, distribuídos aleatoriamente na micrografia (Figura 6d). O tamanho dos aglomerados para a amostra com $\mathrm{Cu}^{2+}$, variou entre 6 e 44,66 $\mu \mathrm{m}$, com tamanho médio de $16,09 \mu \mathrm{m}$.

DANTAS [11], estudando as ferritas de $\mathrm{Ni}-\mathrm{Zn}$ pura e dopadas com $\mathrm{Cu}^{2+}$ como catalisadores para produção de biodiesel, observou durante as sínteses, que em temperaturas mais elevadas, em torno de $900^{\circ} \mathrm{C}$, a morfologia das amostras apresentou maior porosidade, e atribuiu este fato a maior liberação de gases observada experimentalmente. COSTA et al. [33], estudando a síntese e caracterização de ferritas Ni-Cu-Zn, observaram semelhantemente, o ocorrido para ambas amostras deste trabalho, que as micrografias apresentaram morfologia constituída por aglomerados moles de nanopartículas inferiores a $100 \mathrm{~nm}$. SANTOS et al. [34], estudando ferritas Ni-Zn como sintetizadas e silanizadas, observaram semelhantemente, a presença de aglomerados na forma de blocos irregulares de aspecto frágil.

As Figuras 7 e 8 ilustram, respectivamente, as micrografias com o mapeamento dos elementos presentes nas nanoferritas mistas $\mathrm{Ni}_{0,5} \mathrm{Zn}_{0,5} \mathrm{Fe}_{2} \mathrm{O}_{4}$ e $\mathrm{Ni}_{0,2} \mathrm{Cu}_{0,3} \mathrm{Zn}_{0,5} \mathrm{Fe}_{2} \mathrm{O}_{4}$. A partir do mapeamento realizado por EDS acoplado ao $\mathrm{MEV}$, foi possível a identificação e avaliação da distribuição dos elementos $\mathrm{Ni}, \mathrm{Zn}, \mathrm{Cu}, \mathrm{Fe}$ e $\mathrm{O}$, que são os constituintes principais dos espinélios inversos estudados. De forma geral, observou-se nos espectros de EDS, picos característicos do $\mathrm{Ni}, \mathrm{Zn}$, Fe e $\mathrm{O}$ para amostra $\mathrm{Ni}_{0,5} \mathrm{Zn}_{0,5} \mathrm{Fe}_{2} \mathrm{O}_{4}$, e para amostra $\mathrm{Ni}_{0,2} \mathrm{Cu}_{0,3} \mathrm{Zn}_{0,5} \mathrm{Fe}_{2} \mathrm{O}_{4}$, além destes mesmos picos, também se verificou a presença do pico característico do $\mathrm{Cu}$. Os picos em ambas as amostras são provenientes da fase espinélio das ferritas. Além disso, verificou-se ainda que todos estes elementos identificados nas micrografias se encontram bem distribuídos.

Mediante a Figura 7, verificou-se também que a concentração do ferro identificado com a cor rosa (Figura 7c) foi à maior, comprovando que a ferrita é constituída em sua maioria por óxidos a base de ferro, resultado que está em concordância com o teor de óxido de ferro $\left(\mathrm{Fe}_{2} \mathrm{O}_{3}\right)$ identificado na amostra, que foi de $68,4 \%$ obtido pelo EDX. A quantidade de níquel representada pela cor roxa (Figura 7d), e zinco representado pela cor vermelha (Figura 7e), apareceram em menor quantidade, e também revelaram boa distribuição na amostra. Os dados de EDX identificaram valores de 16,161 e 17,113\% para os óxidos de $\mathrm{NiO}$ e $\mathrm{ZnO}$, respectivamente. O oxigênio que aparece mapeado na cor verde (Figura 7b), também indica boa distribuição. Assim, o mapeamento indicou que a amostra confirma a estequiometria da fase da ferrita. 


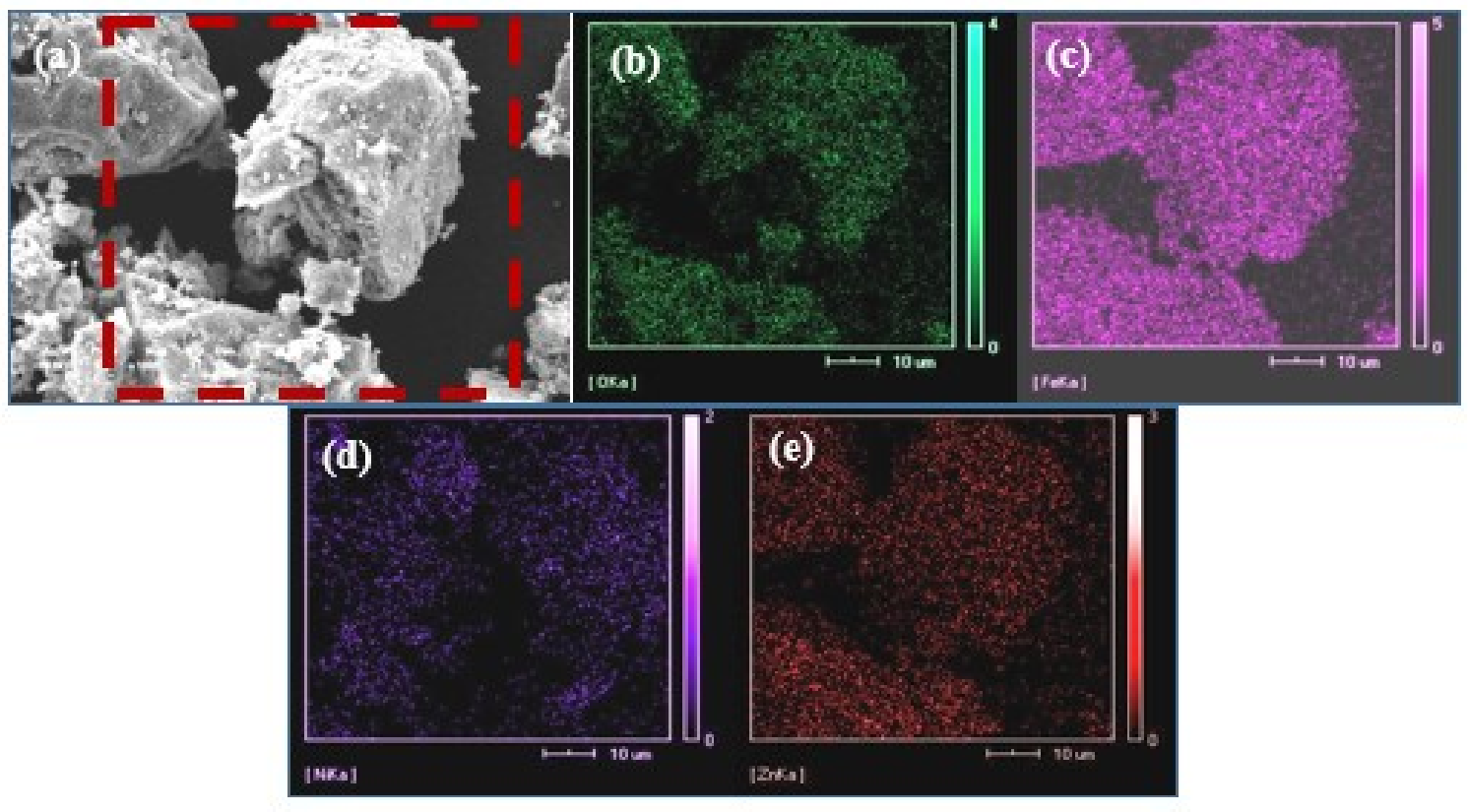

Figura 7: Imagens de MEV com análise de EDS para a ferrita $\mathrm{Ni}_{0,5} \mathrm{Zn}_{0,5} \mathrm{Fe}_{2} \mathrm{O}_{4}$ : (a) micrografia, (b) mapeamento do $\mathrm{O}$ (verde), (c) mapeamento do $\mathrm{Fe}$ (rosa), (d) mapeamento do Ni (roxo) e (e) mapeamento do Zn (vermelho).

Mediante a Figura 8, observou-se que além do mesmo comportamento dos íons distribuídos no espi-

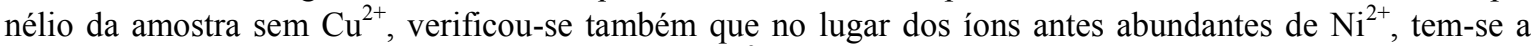
presença abundante e a distribuição dos íons de $\mathrm{Cu}^{2+}$. Pois, para este espinélio $\mathrm{Ni}_{0,2} \mathrm{Cu}_{0,3} \mathrm{Zn}_{0,5} \mathrm{Fe}_{2} \mathrm{O}_{4}$ teve a substituição de $0,3 \mathrm{~mol} \mathrm{de} \mathrm{Ni}^{2+}$ por íons de $\mathrm{Cu}^{2+}$, sendo, portanto, identificado os elementos constituintes $\mathrm{O}$, $\mathrm{Fe}, \mathrm{Zn}$, Ni e Cu. Logo, verificou-se que a síntese de combustão foi eficiente na obtenção do espinélio com boa distribuição dos elementos presentes.

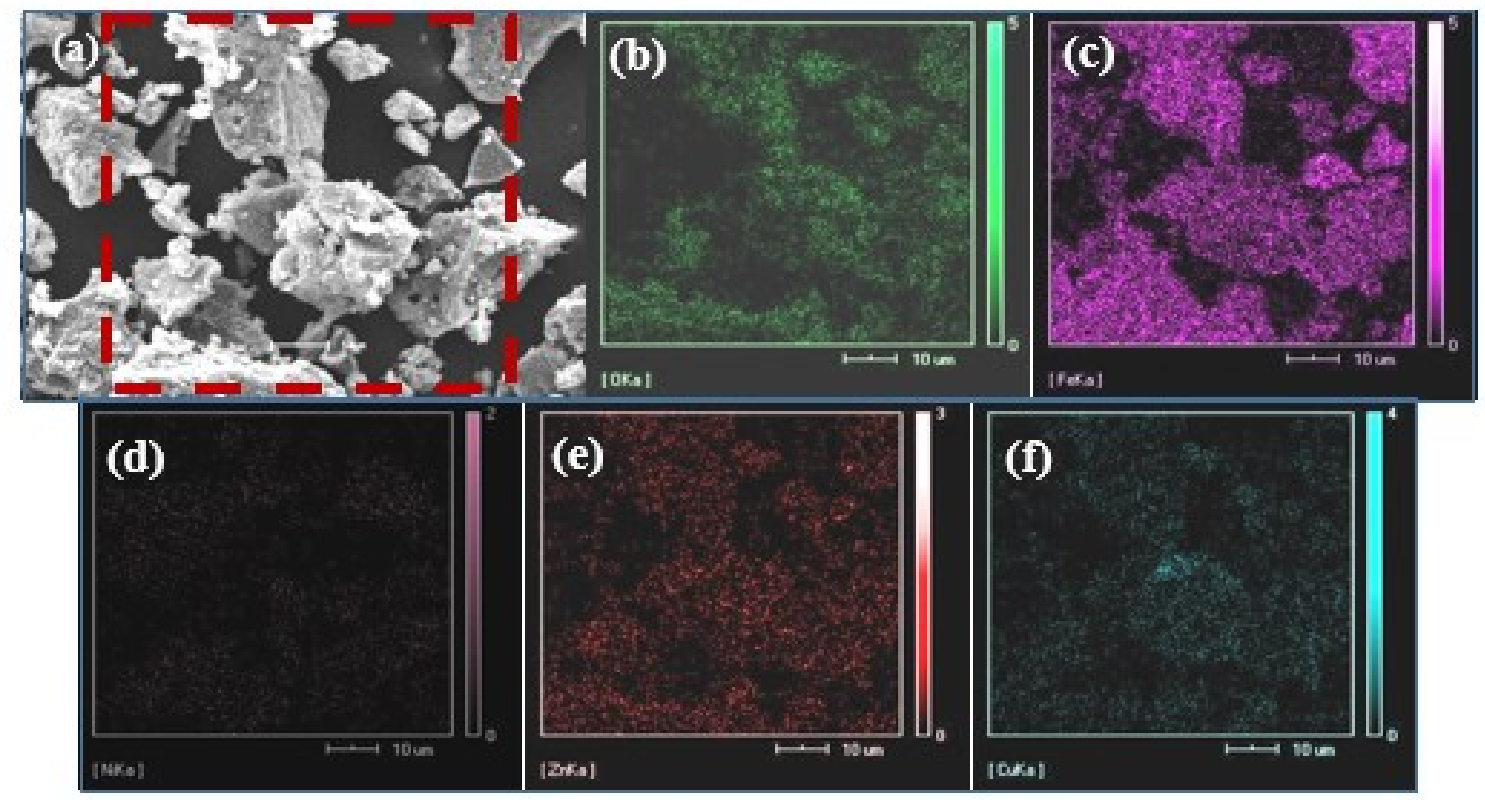

Figura 8: Imagens de MEV com análise de EDS para a nanoferrita $\mathrm{Ni}_{0,2} \mathrm{Cu}_{0,3} \mathrm{Zn}_{0,5} \mathrm{Fe}_{2} \mathrm{O}_{4}$, dopada com 0,3 mol de $\mathrm{Cu}^{2+}$ : (a) micrografia, (b) mapeamento do $\mathrm{O}$ (verde), (c) mapeamento do $\mathrm{Fe}$ (rosa), (d) mapeamento do Ni (roxo), (e) mapeamento do zinco (vermelho) e (f) mapeamento do $\mathrm{Cu}$ (azul). 
Comparando o mapeamento dos íons de $\mathrm{Fe}, \mathrm{Zn}$ e $\mathrm{O}$ (Figura 7) identificado para a amostra sem $\mathrm{Cu}^{2+}$, com o mapeamento identificado na Figura 8, para a amostra com $\mathrm{Cu}^{2+}$, se verificou uma boa coerência relacionada. Com relação aos íons de $\mathrm{Ni}$ (Figura 7d) identificado na amostra sem $\mathrm{Cu}^{2+}$, verificou-se um teor bem mais elevado quando comparado com a presença deste elemento identificado na amostra com $\mathrm{Cu}^{2+}$, (Figura 8e), o que comprovou a efetiva substituição dos íons de $\mathrm{Ni}^{2+}$ por íons de $\mathrm{Cu}^{2+}$, como pode ser visto pela concentração elevada identificada no mapeamento da Figura 8f. Pelo EDX, verifica-se que o teor deste óxido presente na amostra com $\mathrm{Cu}^{2+}$ foi de $8,4 \%$.

Na Figura 9 encontram-se ilustradas as isotermas de adsorção/dessorção de $\mathrm{N}_{2}$ a $77 \mathrm{~K}$, como resultado da caracterização textural das ferritas mistas $\mathrm{Ni}_{0,5} \mathrm{Zn}_{0,5} \mathrm{Fe}_{2} \mathrm{O}_{4} \mathrm{e} \mathrm{Ni}_{0,2} \mathrm{Cu}_{0,3} \mathrm{Zn}_{0,5} \mathrm{Fe}_{2} \mathrm{O}_{4}$. A linha tracejada na cor preta representa a adsorção (condensação de líquido nos poros) e a linha tracejada na cor vermelha representa dessorção (evaporação de líquidos nos poros). O estudo do fenômeno de adsorção foi feito com o objetivo de se obter informações sobre a área específica e a estrutura porosa do sólido, visto a construção da isoterma de adsorção ser de fundamental importância, pois sua forma revela detalhes sobre a característica morfológica do material.
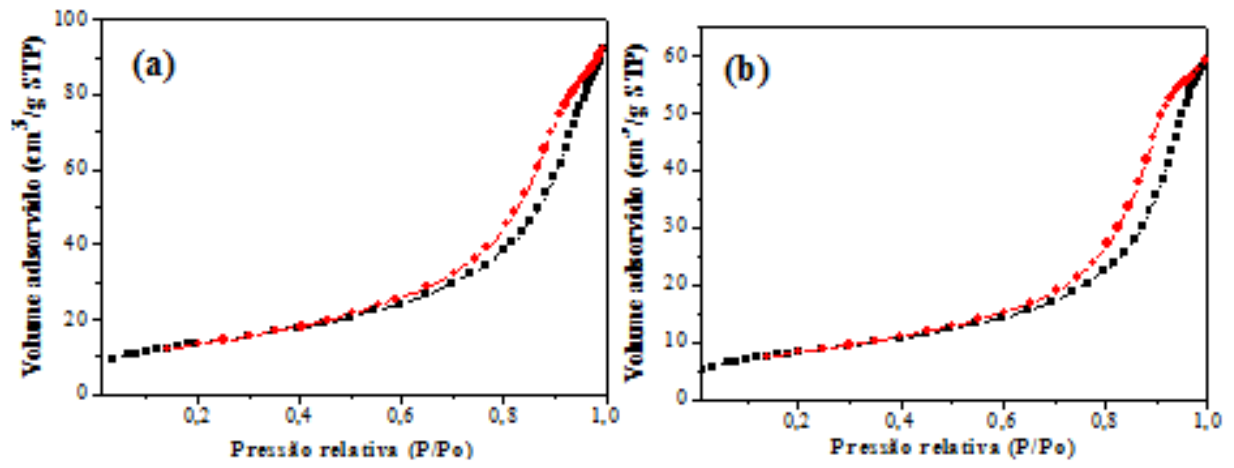

Figura 9: Isotermas de adsorção/dessorção de nitrogênio para: (a) $\mathrm{Ni}_{0,5} \mathrm{Zn}_{0,5} \mathrm{Fe}_{2} \mathrm{O}_{4} \mathrm{e}$ (b) $\mathrm{Ni}_{0,2} \mathrm{Cu}_{0,3} \mathrm{Zn}_{0,5} \mathrm{Fe}_{2} \mathrm{O}_{4}$.

Observou-se que o $\mathrm{Cu}^{2+}$ na amostra $\mathrm{Ni}_{0,5} \mathrm{Zn}_{0,5} \mathrm{Fe}_{2} \mathrm{O}_{4}$, não interferiu no comportamento das curvas de adsorção/dessorção. Ambas as amostras estudadas apresentaram estruturas de superfícies iguais, ou seja, apresentaram o mesmo perfil da curva isoterma de adsorção (BET), que de acordo com a classificação da IUPAC se enquadra no tipo $\mathrm{V}$, sugerindo uma característica mesoporosa do material (poros com raios variando de 10 a $250 \AA$ ). No perfil de isoterma do tipo $\mathrm{V}$ as moléculas do adsorvato apresentam maior interação entre si do que com o sólido. Analisando também as formas de histereses que correspondem a diferentes geometrias de poros, pode-se inferir que as amostras são representadas por loop de histerese tipo 3 (H3) que constituí a formação de poros com formato de cunha, cones ou placas paralelas.

$\mathrm{Na}$ Tabela 3 encontram-se os valores de área superficial específica $\left(\mathrm{S}_{\mathrm{BET}}\right)$, tamanho de partícula $\left(\mathrm{D}_{\mathrm{BET}}\right)$, volume do poro $(\mathrm{Vp})$, raio do poro $(\mathrm{Rp})$ e a relação entre o tamanho de partícula e o tamanho de cristalito $(\mathrm{Tc})$, referente as duas amostras. Os dados apresentados revelam que o maior valor de área superficial específica, de $48,89 \mathrm{~m}^{2} \mathrm{~g}^{-1}$, foi obtido pela amostra sem $\mathrm{Cu}^{2+}\left(\mathrm{Ni}_{0,5} \mathrm{Zn}_{0,5} \mathrm{Fe}_{2} \mathrm{O}_{4}\right)$ e o valor de área superficial foi de $29,89 \mathrm{~m}^{2} \mathrm{~g}^{-1}$, para a amostra dopada com $\mathrm{Cu}^{2+}\left(\mathrm{Ni}_{0,2} \mathrm{Cu}_{0,3} \mathrm{Zn}_{0,5} \mathrm{Fe}_{2} \mathrm{O}_{4}\right)$. Consequentemente, ambas as amostras apresentaram respectivamente, o menor $(23 \mathrm{~nm})$ e o maior $(37 \mathrm{~nm})$ valor do tamanho de partículas.

Tabela 3: Valores de área superficial específica, tamanho de partícula, volume e diâmetro de poro para $\mathrm{Ni}_{0,5} \mathrm{Zn}_{0,5} \mathrm{Fe}_{2} \mathrm{O}_{4} \mathrm{e}$ $\mathrm{Ni}_{0,2} \mathrm{Cu}_{0,3} \mathrm{Zn}_{0,5} \mathrm{Fe}_{2} \mathrm{O}_{4}$.

\begin{tabular}{c|c|c|c|c|c}
\hline \hline AMOSTRAS & $\begin{array}{c}\mathbf{S}_{\text {BET }} \\
\left(\mathbf{m}^{2} \mathbf{g}^{-1}\right)\end{array}$ & $\begin{array}{c}\mathbf{D}_{\text {BET }} \\
(\mathbf{n m})\end{array}$ & $\begin{array}{c}\mathbf{V p} \\
\left(\mathbf{c m}^{\mathbf{3}} \cdot \mathbf{g}^{-\mathbf{1}} \mathbf{)}\right.\end{array}$ & $\begin{array}{c}\mathbf{R p} \\
(\mathbf{A})\end{array}$ & $\mathbf{D}_{\mathrm{BET}} / \mathbf{T c}^{*}$ \\
\hline \hline $\mathrm{Ni}_{0,5} \mathrm{Zn}_{0,5} \mathrm{Fe}_{2} \mathrm{O}_{4}$ & 48,89 & 23 & 0,134 & 109,85 & 0,9 \\
\hline $\mathrm{Ni}_{0,2} \mathrm{Zn}_{0,5} \mathrm{Cu}_{0,3} \mathrm{Fe}_{2} \mathrm{O}_{4}$ & 29,89 & 37 & 0,084 & 113,13 & 1,1 \\
\hline \hline
\end{tabular}

$* \mathrm{Tc}=$ Tamanho de cristalito.

De forma geral, os resultados de área superficial específica, apresentados na Tabela 3, indicam, que esses valores diminuíram aproximadamente $38,85 \%$ com a adição de cobre no sistema $\mathrm{Ni}_{0,5} \mathrm{Zn}_{0,5} \mathrm{Fe}_{2} \mathrm{O}_{4}, \mathrm{le}$ - 
vando ao aumento no tamanho das partículas. Com a presença de $\mathrm{Cu}^{2+}$, observou-se ainda que o volume de poros diminui, e que o tamanho da partícula aumenta, consequentemente o raio do poro aumenta também. Isto possivelmente ocorreu devido a temperatura desenvolvida durante a combustão ter sido maior para a amostra com $\mathrm{Cu}^{2+}$, o que favoreceu consequentemente um aumento no tamanho de partícula (porque obtiveram mais energia para crescerem), ocasionando desta forma, uma redução da porosidade interpartícula, possibilitando uma diminuição no volume dos poros. Os valores do tamanho de partícula estão em concordância com os resultados obtidos para o tamanho de cristalito, pois a amostra com cobre favoreceu o seu aumento, diminuindo com isto, a área superficial específica. Ainda, observou-se por meio dos valores da relação tamanho de partícula/tamanho de cristalito (DвEт/tc), que houve um aumento com a dopagem de $\mathrm{Cu}^{2+}$ indicando desta forma que a amostra ficou mais policristalina, ou seja, com a presença de mais cristais por partícula. No entanto, é conhecido que quanto mais próximo de 1 for esta relação, mais sugere que o tamanho de partícula é próximo do tamanho do cristal, indicando desta maneira que a partícula tende a ser monocristalina. Porém, observou-se que a amostra sem $\mathrm{Cu}^{2+}$ obteve um valor menor que 1, ou seja, com partículas muito finas (nanométricas). Então, observou-se que esta relação foi maior para amostra $\mathrm{Ni}_{0,2} \mathrm{Cu}_{0,3} \mathrm{Zn}_{0,5} \mathrm{Fe}_{2} \mathrm{O}_{4}$, o que indica que o estado de aglomeração tornou-se maior com a presença de cobre no sistema $\mathrm{Ni}_{0,5-\mathrm{x}} \mathrm{Cu}_{\mathrm{x}} \mathrm{Zn}_{0,5} \mathrm{Fe}_{2} \mathrm{O}_{4}$.

Com relação ao tamanho de partícula obtido pela área superficial, um gás $\left(\mathrm{N}_{2}\right)$ é que passa entre as partículas, logo quanto mais finas elas forem e mais porosidade interpartícula existir, a leitura feita na passagem do gás indicará uma maior área superficial, que é a área de contato.

A Figura 10 ilustra os resultados alcançados mediante a utilização das ferritas mistas $\mathrm{Ni}_{0,5} \mathrm{Zn}_{0,5} \mathrm{Fe}_{2} \mathrm{O}_{4} \mathrm{e}$ $\mathrm{Ni}_{0,2} \mathrm{Cu}_{0,3} \mathrm{Zn}_{0,5} \mathrm{Fe}_{2} \mathrm{O}_{4}$, como nanocatalisadores nas reações químicas de transesterificação e esterificação, por intermédio das rotas metílica e etílica do óleo de soja para obtenção de biodiesel.

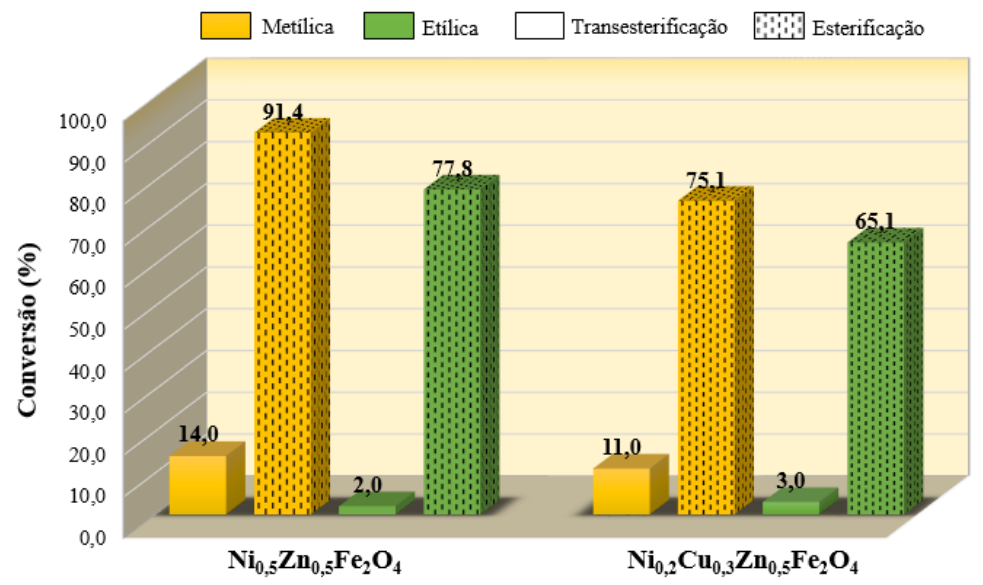

Figura 10: Conversão em ésteres metílicos e etílicos para: $\mathrm{Ni}_{0,5} \mathrm{Zn}_{0,5} \mathrm{Fe}_{2} \mathrm{O}_{4}$ e $\mathrm{Ni}_{0,2} \mathrm{Cu}_{0,3} \mathrm{Zn}_{0,5} \mathrm{Fe}_{2} \mathrm{O}_{4}$ - (A) Transesterificação e (B) Esterificação.

De maneira geral, observou-se que as amostras avaliadas na reação de esterificação metílica e etílica, apresentaram conversões significativamente mais satisfatórias, em detrimento da reação de transesterificação metílica e etílica. Entretanto, observa-se também que tanto na transesterificação quanto na esterificação, as amostras foram mais ativas com a utilização do álcool metanol. Isto possivelmente ocorreu por ser o metanol mais reativo, enquanto que os ésteres etílicos possuem maior afinidade à glicerina, dificultando assim a sua separação. Ou seja, estes resultados podem ser atribuídos ao fato de que as reações de transesterificação e esterificação pela rota etílica é significativamente mais complexa do que pela metílica, pois, com o aumento da cadeia carbônica do álcool utilizado, maior o impedimento espacial do álcool com o triacilglicerídeo.

Assim, observa-se que ambas amostras $\mathrm{Ni}_{0,5} \mathrm{Zn}_{0,5} \mathrm{Fe}_{2} \mathrm{O}_{4}$ e $\mathrm{Ni}_{0,2} \mathrm{Cu}_{0,3} \mathrm{Zn}_{0,5} \mathrm{Fe}_{2} \mathrm{O}_{4}$, respectivamente, apresentaram na esterificação, conversões dos ácidos graxos em ésteres de 91,4 e 75,1\% na metanólise, e de 77,8 e $65,1 \%$ na etanólise. Enquanto que na reação de transesterificação, as conversões foram respectivamente de 14 e $11 \%$ na metanólise, e de 2 e $3 \%$ na etanólise. Levando em consideração os maiores valores de conversão na esterificação, que foi de $91,4 \%$ na rota metílica, e de $77,8 \%$ na rota etílica, houve uma diferença de aproximadamente $14 \%$ a favor da metílica. Na transesterificação, cujos valores foram de $14 \%$ com o metanol e de $3 \%$ com o etanol, houve uma diferença de $11 \%$ a favor também do metanol. Isto possivelmente ocorreu porque, em relação ao álcool, o metanol é o mais usado nestas reações por razões de natureza física e química (cadeia curta e polaridade), levando a maiores conversões. 
Então, o conjunto destas características de possuir cadeia curta e polaridade, somado ao fato de também ser o metanol isento de água, isto torna mais fácil a separação entre os ésteres e a glicerina, culminando em maiores conversões. Assim, possivelmente a água presente no etanol interferiu, por exemplo, na reação de transesterificação, reduzindo a quantidade de produto transesterificado, e propiciou a formação de emulsão na mistura dos ésteres devido à saponificação do óleo vegetal.

Logo, o tipo de álcool, além do catalisador, pode ser possivelmente atribuído como um dos fatores preponderantes para a disparidade nas conversões provenientes das reações de transesterificação e esterificação, visto que os demais parâmetros envolvidos nos processos foram mantidos sem alterações. Isto pode ser respaldado pelo relato de MURUGESAN et al. [35], que os ésteres etílicos apresentam maior dificuldade de formação quando comparados com os ésteres metílicos, o biodiesel produzido do etanol possui a viscosidade cinemática maior que o biodiesel produzido de metanol. Os autores relataram também que durante a reação de transesterificação pode haver a formação de emulsões, devido a não miscibilidade do etanol com os triacilglicerídeos, o que dificulta a separação e purificação dos ésteres.

Outro fator possível de ser atribuído é o de que muito embora a literatura reporte que os sítios ácidos de Brönsted presentes nos catalisadores são mais adequados para a reação esterificação [36], a atividade das ferritas em estudo pode estar relacionada com a presença de sítios ácidos de Lewis, mesmo que em pouca quantidade. Os autores sugerem que para a reação de esterificação, os ácidos de Lewis podem ser mais adequados que os ácidos de Brönsted, principalmente porque na presença destes sítios, a desidratação e a racemização do álcool envolvido podem ser evitadas [37].

Além disso, um fator igualmente relevante para se atribuir a conversão mais elevada para a amostra $\mathrm{Ni}_{0,5} \mathrm{Zn}_{0,5} \mathrm{Fe}_{2} \mathrm{O}_{4}$, está relacionada as suas características estruturais e morfológicas, no que diz respeito ao seu menor tamanho de cristalito quando comparado a amostra $\mathrm{Ni}_{0,2} \mathrm{Cu}_{0,3} \mathrm{Zn}_{0,5} \mathrm{Fe}_{2} \mathrm{O}_{4}$, bem como a sua morfologia composta por aglomerados maiores e principalmente a sua elevada área de superfície (requisito importantíssimo na catálise). Estas características contribuem para se obter um catalisador com probabilidade de maior número de sítios ácidos ativos e consequentemente com maior área de contato entre os demais reagentes (álcool e ácido graxo), de forma a propiciar um meio reacional mais eficiente para a conversão em ésteres.

Ademais, também se pode atribuir para o superior desempenho da ferrita $\mathrm{Ni}_{0,5} \mathrm{Zn}_{0,5} \mathrm{Fe}_{2} \mathrm{O}_{4}$, o seu menor valor de temperatura máxima alcançada durante a sua síntese em detrimento a maior temperatura alcançada pela amostra $\mathrm{Ni}_{0,2} \mathrm{Cu}_{0,3} \mathrm{Zn}_{0,5} \mathrm{Fe}_{2} \mathrm{O}_{4}$, visto que a temperatura impõe alterações diretas na superfície do material. Segundo TANG et al. [38], em temperaturas superiores a $1000^{\circ} \mathrm{C}$, as alterações de superfície são mais pronunciadas. Em alguns casos, essas modificações reduzem consideravelmente a área de superfície e os sítios ativos dos catalisadores.

Portanto, fatores como o tipo de álcool utilizado, características estruturais e morfológicas dos catalisadores, bem como as suas condições de síntese (como temperatura alcançada), podem ser atribuídas e estão diretamente relacionadas a performance catalítica nas reações de transesterificação e esterificação. Desta maneira, fica evidenciada a potencial viabilidade da aplicação de nanoferritas mistas obtidas por reação de combustão como promissores catalisadores heterogêneos para obtenção de biodiesel.

\section{CONCLUSÕES}

A síntese por reação de combustão empregada para a produção de nanocatalisadores a base de ferritas mistas de $\mathrm{Ni}_{0,5} \mathrm{Zn}_{0,5} \mathrm{Fe}_{2} \mathrm{O}_{4}$ e $\mathrm{Ni}_{0,2} \mathrm{Cu}_{0,3} \mathrm{Zn}_{0,5} \mathrm{Fe}_{2} \mathrm{O}_{4}$, foi eficiente para obtenção de um produto final monofásico, com boa distribuíção de todos os elementos componentes em sua estrutura e potencialmente ativos para catalisar reações de esterificação. As características estruturais e morfológicas contribuíram diretamente no desempenho catalítico das ferritas. A ferrita $\mathrm{Ni}_{0,5} \mathrm{Zn}_{0,5} \mathrm{Fe}_{2} \mathrm{O}_{4}$ foi mais ativa como nanocatalisador para as reações químicas de esterificação metílica e etílica do óleo de soja, apresentando uma maior eficiência na esterificação metílica, com conversão dos ácidos graxos de $91,4 \%$ em detrimento à rota etílica que foi de $77,4 \%$. Nanocatalisadores com estrutura tipo espinélio são materiais promissores para catalisar as reações químicas para obtenção de biodiesel.

\section{AGRADECIMENTOS}

Os autores agradecem a CAPES, ao CNPq e ao Inct-INAMI, pelo apoio financeiro. 


\section{BIBLIOGRAFIA}

[1] WELDEMICHAEL, Y., ASSEFA, G., “Assessing the energy production and GHG (greenhouse gas) emissions mitigation potential of biomass resources for Alberta", Journal of Cleaner Production, v. 112, pp. 4257-4264, 2016.

[2] BRITO, J.F., FERREIRA, L.O., SILVA, J.P., et al., "Tratamento da água de purificação do biodiesel utilizando eletrofloculação”, Química Nova, v. 35, n. 4, pp. 1-5, 2012.

[3] KONWAR, L.J., WÄRNÅ, J., MÄKI-ARVELA, P., et al., "Reaction kinetics with catalyst deactivation in simultaneous esterification and transesterification of acid oils to biodiesel (FAME) over a mesoporous sulphonated carbon catalyst", Fuel, v. 166, pp. 1-11, 2016.

[4] DEMIRBAS, A., "Studies on cottonseed oil biodiesel prepared in non-catalytic SCF conditions", Bioresource Technology, v. 99, n. 5, pp. 1125-1130, 2008.

[5] SHENGYANG, H., YANPING, G., YUN, W., et al., "Nano-magnetic catalyst $\mathrm{KF} / \mathrm{CaO}-\mathrm{Fe}_{3} \mathrm{O}_{4}$ for biodiesel production", Applied Energy, v. 88, n. 8, pp. 2685-2690, 2011.

[6] SANKARANARAYANAN, T.M., SHANTHIA, R.V., THIRUNAVUKKARASU, K., et al., "Catalytic properties of spinel-type mixed oxides in transesterification of vegetable oils", Journal of Molecular Catalysis A: Chemical, v. 379, pp. 234-242, 2013.

[7] SEO, J.Y., LEE, K., LEE, S.Y., et al., "Effect of barium ferrite particle size on detachment efficiency in magnetophoretic harvesting of oleaginous Chlorella sp”, Bioresource Technology, v. 152, pp. 562-566, 2014.

[8] XUE, B.-J., LUO, J., ZHANG, F., et al., "Biodiesel production from soybean and Jatropha oils by magnetic $\mathrm{CaFe}_{2} \mathrm{O}_{4}-\mathrm{Ca}_{2} \mathrm{Fe}_{2} \mathrm{O}_{5}$-based catalyst", Energy, v. 68, pp. 584-591, 2014.

[9] GURUNATHAN, B., RAVI, A., "Process optimization and kinetics of biodiesel production from neem oil using copper doped zinc oxide heterogeneous nanocatalyst", Bioresource Technology, v. 190, pp. 424$428,2015$.

[10] ZHANG, F., FANG, Z., WANG, Y-T., "Biodiesel production directly from oils with high acid value by magnetic $\mathrm{Na}_{2} \mathrm{SiO}_{3} @ \mathrm{Fe}_{3} \mathrm{O}_{4} / \mathrm{C}$ catalyst and ultrasound”, Fuel, v. 150, pp. 370-377, 2015.

[11] DANTAS, J., Síntese e avaliação do desempenho de catalisadores a base de ferritas Ni-Zn dopada com cobre na reação de transesterificação de óleo vegetal em biodiesel, Dissertação de M.Sc., Pós-Graduação em Ciências e Engenharia de Materiais/UFCG, Campina Grande, PB, Brasil, 127f, 2012.

[12] ATA-ALlAH, S.S., BALAGUROV, A.M., HASHHASH, A., et al., "Refinement of atomic and magnetic structures using neutron diffraction for synthesized bulk and nano-nickel zinc gallate ferrite," Physica B: Condensed Matter, v. 481, pp. 118-123, 2016.

[13] SRINIVAS, CH., TIRUPANYAM, B.V., MEENA, S.S., et al., "Structural and magnetic characterization of co-precipitated $\mathrm{Ni}_{x} \mathrm{Zn}_{1-x} \mathrm{Fe}_{2} \mathrm{O}_{4}$ ferrite nanoparticles", Journal of Magnetism and Magnetic Materials, v. 407, pp. 135-141, 2016.

[14] CHEN, W., ZHOU, Y., LU, J., et al., "Effects of $\mathrm{Li}^{+}$substitution on the structural and magnetic properties of $\mathrm{Co}_{0.5} \mathrm{Mn}_{0.5} \mathrm{Fe}_{2} \mathrm{O}_{4}$ particles", Ceramics International, v. 42, pp. 1114-1121, 2016.

[15] AHMAD, I., ABBAS, T., ZIYA, A.B., et al., "Structural and magnetic properties of erbium doped nanocrystalline Li-Ni ferrites”, Ceramics International, v. 140, pp. 7941-7945, 2014.

[16] SAFFARI, F., KAMELI, P., RAHIMI, M., et a., "Effects of Co-substitution on the structural and magnetic properties of $\mathrm{NiCo}_{x} \mathrm{Fe}_{2-x} \mathrm{O}_{4}$ ferrite nanoparticles”, Ceramics International, v. 41, pp. 7352-7358, 2015.

[17] DANTAS, J., SILVA, A.S., SANTOS, P.T.A., et al., "Evaluation of catalyst $\mathrm{Ni}_{0.4} \mathrm{Cu}_{0.1} \mathrm{Zn}_{0.5} \mathrm{Fe}_{2} \mathrm{O}_{4}$ on methyl esterification of free fatty acid present in cottonseed oil", Materials Science Forum, v. 727-728, pp. 1302-1307, 2012a.

[18] DANTAS, J., SANTOS, J. R. D., CUNHA, R. B. L., et al., "Use of Ni-Zn Ferrites Doped with Cu as Catalyst in the Transesterification of Soybean Oil to Methyl Esters", Materials Research, v. 16, n. 3, pp. 625 $627,2013$.

[19] DANTAS, J., SILVA, F.N., PEREIRA, K.R.O., et al., "Evaluation of the Processing Conditions in the Transesterification for Biodiesel Production Using the Nanomagnetic Catalyst $\mathrm{Ni}_{0.5} \mathrm{Zn}_{0.5} \mathrm{Fe}_{2} \mathrm{O}_{4}$ ", Materials Science Forum, v. 820, pp. 113-118, 2015. 
DANTAS, J.; LEAL, E.; MAPOSSA, A.B.; SILVA, A.S.; COSTA, A.C.F.M. revista Matéria, v. 21, n.4, pp. 1080 - 1093 , 2016.

[20] DANTAS, J., SANTOS, J.R.D., CUNHA, R.B.L., et al., "Síntese das nanoferritas Cu-Zn e Ni-Zn e avaliação do desempenho como catalisador na esterificação metílica para produção de biodiesel", In: VII Encontro Técnico de Materiais e Química, Rio de Janeiro, Brasil, 2012b.

[21] SILVA, A.S., DANTAS, J., SANTOS, J.R.D., et al., "Synthesis, characterization and catalytic performance of nanoferrites subjected to the esterification reaction", Materials Science Forum, v. 775-776, pp. 421-426, 2014

[22] DANTAS, J., SILVA, A.S., COSTA, A.C.F.M., et al., "Síntese, caracterização dos espinélios $\mathrm{NiFe}_{2} \mathrm{O}_{4} \mathrm{e}$ $\mathrm{CoFe}_{2} \mathrm{O}_{4}$ e avaliação do desempenho na transesterificação e esterificação do óleo de algodão", Revista Eletrônica de Materiais e Processos, v. 7, n. 3, pp. 174-179, 2012c.

[23] JAIN, S.R., ADIGA, K.C., VERNEKER, V.P., "A new approach to thermo chemical calculations of condensed fuel”, Combustion and Flame, v. 40, pp. 71-79, 1981.

[24] COSTA, A.C.F.M., KIMINAMI, R.H.G.A., Dispositivo para produção de nanomateriais cerâmicos em larga escala por reação de combustão e processo contínuo de produção dos nanomateriais. Depósito de patente, Revista de Propriedade Industrial - RPI, depositada em 25/01/2012, nº BR 102012 002181-3.

[25] KLUNG, H., ALEXANDER, L., In X-ray diffraction procedures, $1^{\mathrm{a}}$ ed., 495, Wiley, New York, EUA, 1962.

[26] COSTA, A.C.F.M., PORTELLA, E., MORELLI, M.R., et al , "Combustion Synthesis: Effect of Urea on the Reaction and Characterization of Ni-Zn Ferrite Powders", Journal of Materials Synthesis and Processing, v. 9, n. 6, pp. 347-352, 2002.

[27] BATOO, K.M., ANSARI, M.S., "Low temperature-fired Ni-Cu-Zn ferrite nanoparticles through autocombustion method for multilayer chip inductor application", Nanoscale Research Letters, v. 7, n. 1, pp. 112 , 2012 .

[28] GHASEMI, A., GHASEMI, E., PAIMOZD, E., "Influence of copper cations on the magnetic properties of NiCuZn ferrite nanoparticles", Journal of Magnetism and Magnetic Materials, v. 323, pp. 1541-1545, 2011.

[29] VELMURUGAN, K., VENKATACHALAPATHYV, S.K., SENDHILNATHAN S, "Synthesis of Nickel Zinc Iron Nanoparticles by Coprecipitation Technique”, Materials Research, v.13, n. 3, pp. 299-303, 2010.

[30] STASZAK, W., ZAWADZKI, M., OKAL, J. "Solvothermal synthesis and characterization of nanosized zinc aluminate spinel used in iso-butane combustion", Journal of Alloys and Compounds, v. 492, pp. 500507, 2010.

[31] SHIRSATH, S.E., TOKSHA, B.G., KADAM, R.H., et al., "Doping effect of $\mathrm{Mn}^{2+}$ on the magnetic be havi orin Ni-Zn ferrite nanoparticles prepared by sol-gel auto-combustion", Journal of Physics and Chemistry of Solids, v. 71, pp. 1669-1675, 2010.

[32] REED, J.S., Principles of Ceramic Processing, John Wiley \& Sons, New York, 1994.

[33] COSTA, A.C.F.M., GAMA, L., PORTELA, F.A., et al., Revista Eletrônica de Materiais e Processos, v. 2, pp. 10-17, ISSN 1809-8797, 2007.

[34] SANTOS, P.T.A., DANTAS, J., ARAÚJO, P.M.A.G., et al., "Nanoferrites Ni-Zn silanized with 3aminopropyltrimethoxysilane using the reflux method”, Materials Science Forum, v. 805, pp. 94-99, 2015.

[35] MURUGESAN, A., "Production and analysis of bio-diesel from non-edible oils - A review Renewable and sustainable", Energy Reviews, v.13, pp. 825-834, 2009.

[36] DI SERIO, M., TESSER, R., PENGMEI, L., et al., "Heterogeneous catalysts for biodiesel production", Energy e Fuels, v. 22, n. 1, pp. 207-217, 2007.

[37] NARASIMHARAO, K., LEE, A., WILSON, K., "Catalysts in production of biodiesel: a review", Journal of biobased materials and Bioenergy, v. 1, pp. 19-30, 2007.

[38] TANG, S., WANG, L., ZHANG, Y., et al., "Study on preparation of $\mathrm{Ca} / \mathrm{Al} / \mathrm{Fe}_{3} \mathrm{O}_{4}$ magnetic composite solid catalyst and its application in biodiesel transesterification", Fuel Processing Technology, v. 95, pp. 8489, 2012. 